\title{
Neraca Pemanfaatan Kemiri dan Madu di Taman Nasional Bantimurung Bulusaraung
}

\author{
Auliah Rachmah ${ }^{1 *}$, Supratman $^{2}$, Makkarennu$^{2}$ \\ ${ }^{1}$ Mahasiswa, Laboratorium Kebijakan dan Kewirausahaan, Fakultas Kehutanan, Universitas \\ Hasanuddin, Makassar \\ ${ }^{2}$ Staf Pengajar, Fakultas Kehutanan, Universitas Hasanuddin, Makassar \\ *Email: auliahrachmah.273@gmail.com
}

\begin{abstract}
This study aims to calculate the amount of utilization of candlenut and honey in Bantimurung Bulusaraung National Park. This research has been conducted since December 2016. The research implementation place is in Tompobulu Village, Balocci Sub-district, Pangkep District, South Sulawesi Province. This activity uses participative approach, to get data and information from the community that utilize candlenut and honey. This approach is done through interviews, questionnaires and document/literature tracking by using purposive sampling technique. Physical balance sheet and monetary balance which is utilized by the community analyzed by calculating the amount of initial reserve in the year of research added with the amount of planting, then reduced by the amount of depletion so that will be obtained the final reserve amount. Result of this study obtained the physical balance sheet of honey final reserve is 558 liter, monetary balance sheet of honey final reserve is Rp 115.861.440), physical balance sheet of candlenut final reserve is $1,060 \mathrm{~kg}$, monetary balance sheet of candlenut final reserve is (-Rp 40.113.000).
\end{abstract}

Keywords: Physical Balance Sheet, Monetary Balance Sheet, Candlenut, Honey, Depletion

\section{PENDAHULUAN}

Berdasarkan undang-undang nomor 41 tahun 1999, bahwa hutan adalah suatu kesatuan ekosistem sumberdaya alam hayati beserta lingkungannya yang tidak terpisahkan. Sejak dimulainya pemanfaatan hasil hutan secara besar-besaran di Indonesia, hutan telah dijadikan sebagai modal utama dalam peningkatan ekonomi nasional yang memberikan dampak positif diantaranya peningkatan devisa, kebutuhan tenaga kerja dan meningkatkan pengembangan wilayah serta pertumbuhan ekonomi namun disisi lain pemanfaatan hutan telah menimbulkan berbagai permasalahan sosial dan lingkungan yang dimana terdapat masalah yang tersembunyi namun dapat membahayakan kedepannya, yaitu menurunnya produksi hutan dan kualitas ekonomi masyarakat yang tinggal di sekitar kawasan hutan (Justianto, 2006).

Menurut Kadir (2013), selama ini hutan cenderung dimanfaatkan secara berlebihan yang mengakibatkan kerusakan pada hutan itu sendiri. Cadangan sumberdaya alam merupakan kekayaan yang nyata bagi suatu bangsa. Peranan sumberdaya alam dalam pembangunan adalah sebagai sumber bahan mentah dalam kegiatan produksi dengan terus berkembangnya suatu perekonomian yang diikuti oleh perkembangan jumlah penduduk dan terkurasnya sumberdaya alam dan degradasi lingkungan telah mendorong para pembuat keputusan untuk semakin menyadari dan memikirkan secara lebih serius krisis sumberdaya alam dan lingkungan tersebut (Dewi, 2010).

Pemanfaatan sumberdaya alam secara berlebihan tanpa memperhatikan cara pelestariannya dengan sendirinya akan meningkatkan tekanan terhadap lingkungan hidup yang akan mempengaruhi kecukupan kebutuhan masyarakat kedepannya. Sumberdaya alam merupakan salah satu modal yang perlu dikembangkan dan dioptimalkan untuk menunjang pengembangan suatu wilayah. Namun, pemanfaatan sumber daya alam tersebut harus memperhatikan konservasi dan upaya untuk kelestarian fungsi ekosistemnya. Taman Nasional 
Bantimurung Bulusaraung ( TN Babul ) ditunjuk berdasarkan Surat keputusan Menteri Kehutanan Republik Indonesia Nomor : SK>398/Menhut-II/2004 tanggal 18 Oktober 2004 dengan luas wilayah $\pm 43.750 \mathrm{Ha}$. Secara administratif TN Babul terletak dalam tiga wilayah kabupaten yaitu Kabupaten Maros, Pangkep dan Bone, Provinsi Sulawesi Selatan.

Sejauh ini masyarakat memanfaatkan hasil hutan bukan kayu karena terkendala oleh larangan penebangan di dalan areal TN Babul, menurut Peraturan Menteri No. P35/ Menhut/II/ 2007, hasil hutan bukan kayu (HHBK) adalah hasil hutan hayati baik nabati maupun hewani beserta produk turunan dan budidaya kecuali kayu sebagai segala sesuatu yang bersifat material (bukan kayu) yang dimanfatkan bagi kegiatan ekonomi dan peningkatan kesejahteraan masyarakat. HHBK telah dimanfaatkan oleh masyarakat sekitar hutan baik secara langsung maupun tidak, selain karena HHBK mudah diperoleh dan tidak membutuhkan teknologi yang rumit untuk mendapatkannya juga karena HHBK mempunyai nilai ekonomi. HHBK yang sudah biasa dimanfaatkan dan dikomersilkan diantaranya adalah cendana, kemiri, gaharu, sagu, rotan, aren, sukun, bambu, sutera alam, ernang, kemenyan, kayu putih, aneka tanaman obat, minyak atsiri dan madu (Suhesti dkk., 2015).

Kemiri telah dikelola masyarakat dan merupakan simbol status sosial serta menjadi primadona antara tahun 1960-an sampai 1980 karena menjadi sumber pendapatan utama yang menyejahterakan masyarakat (Yusran, 2005). Sedangkan Madu merupakan produk yang mengandalkan sumber daya alam untuk produksinya secara umum jumlah konsumsi madu di Indonesia baru mencapai 3,2 gram per kapita pertahun, jauh lebih rendah dari Negara-negara berkembang yang lain yaitu 70 gram per kapita pertahunnya. Konsumsi madu di Negara maju mencapai 1000-1600 gram per kapita pertahun (Prihartini,2004).

Namun yang menjadi kendala adalah kurangnya informasi mengenai jumlah besaran cadangan awal hingga cadangan akhir dari pemanfaatan kawasan hutan. Sementara untuk menjaga kestabilan, pemanfaatan hasil hutan perlu dihitung besaran jumlah pemanfaatan salah satunya menggunakan sistem neraca yakni, mencatat tentang jumlah cadangan awal, perubahan perubahannya dan cadangan akhir sumberdaya alam untuk, mengetahui besaran cadangan atau potensi sumberdaya alam tersebut pada suatu wilayah maka neraca sumberdaya alam dan lingkungan pada dasarnya dibedakan menjadi neraca fisik dan neraca moneter.

Neraca fisik dapat menggambarkan perubahan kuantitas sumber daya alam yang mencakup nilai perubahan dalam cadangan awal, penanaman, deplesi dan cadangan akhir dalam satuan berat maupun volume, sedangkan neraca moneter untuk menghitung penerimaan dari sumber daya alam dalam satuan Rupiah, sehingga untuk mendapatkan informasi besaran nilai pemanfaatan, neraca diperlukan untuk memberikan informasi tentang nilai pemanfaatan sumberdaya alam dan lingkungan agar penggunaannya lebih efisien dan bijaksana.

Dari perubahan yang terjadi baik bertambah (surplus) maupun berkurang (defisit) bisa dijadikan dasar penentuan kebijakan pembangunan maka dari itu penelitian ini bertujuan untuk dilakukannya penghitungan jumlah besaran pemanfaatan kemiri dan madu di Taman Nasional Bantimurung Bulusaraung yang masih dapat digunakan kedepannya.

\section{METODE PENELITIAN}

\subsection{Metode Pelaksanaan Penelitian}

Penelitian ini menggunakan pendekatan partisipasif, untuk mendapatkan data dan informasi dari masyarakat yang memanfaatkan hasil hutan bukan kayu. Pendekatan ini dilakukan melalui wawancara, kuesioner dan penelusuran dokumen/literatur. 


\subsection{Teknik Pengumpulan Data}

Data yang dikumpulkan pada penelitian ini terdiri atas data primer dan sekunder. Data primer terdiri atas frekuensi pemanfaatan dan data hasil hutan yang dimanfaatkan oleh masyarakat yang berasal dari komponen-komponen penyusun yakni observasi awal, wawancara dan quisioner. Pengambilan informan menggunakan teknik purposive sampling dimana informan yang diambil sebanyak 10 orang untuk madu dan 10 orang untuk kemiri di masyarakat yang melakukan aktivitas pemanfaatan HHBK kemiri dan madu.

Data sekunder terdiri atas data informasi mengenai TN Babul dan kondisi umum lokasi penelitian yakni desa Tompobulu, kabupaten Pangkep. Data diperoleh melalui studi pustaka dari laporan-laporan hasil penelitian dan buku.

\section{ANALISIS DATA}

\subsection{Neraca Fisik}

Neraca fisik sumberdaya hutan yang di manfaatkan oleh masyarakat di analisis dengan menghitung jumlah cadangan awal dalam bentuk liter ( $\mathrm{l}$ ) untuk madu dan kilogram $(\mathrm{kg})$ untuk kemiri. Cadangan awal pada tahun penelitian ditambah dengan jumlah penanaman, kemudian dikurangi dengan jumlah deplesi sehingga akan diperoleh jumlah cadangan akhir.

Untuk menghitung jumlah cadangan akhir HHBK madu dan kemiri rumusannya adalah :

a. Cadangan awal

Penambahan

b. Deplesi
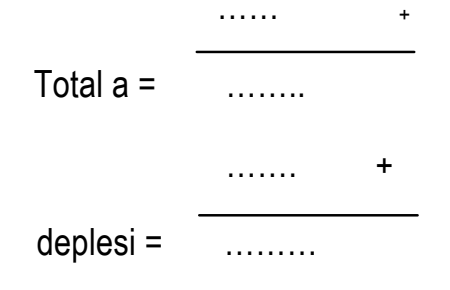

Cadangan akhir $=$ Total $\mathbf{a}-$ deplesi

Keterangan :

- Pada cadangan awal adalah jumlah sumberdaya HHBK pada tahun penelitian

- Satuan Liter untuk Madu dan Kilogram untuk Kemiri

- Cadangan sumberdaya alam yang semakin menipis akan tercermin pada nilai cadangan akhir yang semakin kecil

\subsection{Neraca Moneter}

Neraca moneter hasil hutan yang di manfaatkan oleh masyarakat di hitung dengan menjumlahkan cadangan awal yang di konversi ke satuan uang Rupiah. Jumlah nilai rupiah cadangan awal ditambah dengan penambahan akan di kurangi dengan deplesi sehingga diperoleh jumlah cadangan akhir.

Untuk menghitung neraca moneter menggunakan metode :

a. Cadangan awal

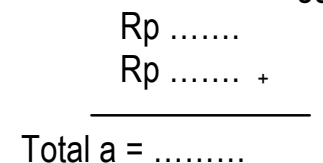

Total $\mathrm{a}=$

Revaluasi

b. Deplesi

$\frac{\mathrm{Rp} \ldots \ldots \ldots+}{\mathrm{Rp} \ldots \ldots .}$


deplesi $=$

Cadangan akhir $=$ Total $a+$ Revaluasi - deplesi

Keterangan :

- Semua nilai dinyatakan dalam satuan uang Rupiah

- Cadangan sumberdaya alam yang semakin menipis akan tercermin pada nilai cadangan akhir yang lebih kecil daripada nilai cadangan awal.

Untuk mendapatkan Nilai deplesi hutan diperoleh dengan mengalikan volume produksi masing-masing jenis sumberdaya hutan yang di manfaatkan oleh masyarakat dengan unit rent atau unit price-nya.

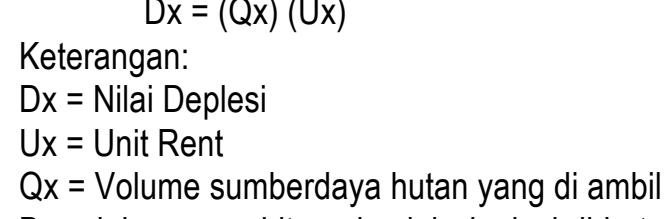

Dan dalam menghitung jumlah deplesi di butuhkan perhitungan unit rent dimana unit rent adalah nilai rente ekonomi per unit yang dimana menggunakan biaya pengambilan per unit termasuk nilai laba per unit yang layak di terima oleh si pengambil dari harga pasar produk sumberdaya hutan.

Harga produk hutan $\quad$ Rp ..........

Biaya produksi

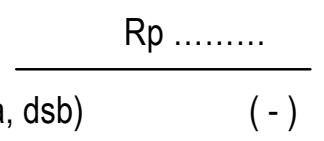

(Bahan, tenaga kerja, sewa, dsb)

$(-)$

Laba kotor per unit

$\mathrm{Rp} \ldots \ldots \ldots$

Laba layak per unit

Rp ............

(suku bunga bank $=$ balas jasa investasi)

$(-)$

Unit Rent produk hutan

$\mathrm{Rp} \ldots \ldots . . .$.

\section{HASIL DAN PEMBAHASAN}

\subsection{Neraca Fisik HHBK Madu}

Neraca fisik menggambarkan mengenai perubahan kuantitas setiap jenis sumber daya alam yang mencakup perubahan-perubahan dalam cadangan awal, pertumbuhan, deplesi dan cadangan akhir. Volume cadangan akhir suatu tahun, akan sama jumlahnya dengan cadangan awal tahun berikutnya. Pemanfaatan HHBK merupakan perubahan dari hasil pemanfaatan manusia terhadap hutan berupa hasil hutan kayu ataupun hasil hutan bukan kayu.

Madu adalah salah satu produk perlebahan yang telah dikenal oleh masyarakat luas di seluruh dunia, termasuk Indonesia seperti di desa Tompobulu kabupaten Pangkep masyarakat memanen madu menggunakan metode tradisional pengasapan yang terbuat dari bambu kering yang di bungkus dengan daun masih segar disebut "Damu". Madu hutan yang di panen berwarna coklat tua dan rasa manis yang berasal dari pohon Enau dan Kemiri. Jenis madu yang di dapatkan masyarakat termasuk golongan madu ekstraflora, madu tersebut dihasilkan oleh lebah-lebah yang hidup di alam liar yang berjenis Apis dorsata. Jenis Apis dorsata ini merupakan jenis lebah hutan yang hingga saat ini di kalangan masyarakat belum dapat dibudidayakan baik dengan cara tertutup maupun dengan cara terbuka (Purbaya, 2007). 
Tabel 1. Jumlah cadangan awal 2017 dan jumlah madu belum dipanen

\begin{tabular}{|c|c|c|c|c|c|c|c|}
\hline \multirow{2}{*}{ No } & \multirow{2}{*}{ Nama } & \multicolumn{2}{|c|}{$\begin{array}{c}\text { Cadangan awal } \\
2017 \\
\end{array}$} & \multicolumn{2}{|c|}{$\begin{array}{l}\text { Jumlah madu belum di } \\
\text { panen }\end{array}$} & \multicolumn{2}{|c|}{$\begin{array}{l}\text { Jumlah madu yang di } \\
\text { panen }\end{array}$} \\
\hline & & Sarang & $\begin{array}{c}\text { Jumlah } \\
\text { (liter) }\end{array}$ & Sarang & $\begin{array}{l}\text { Jumlah } \\
\text { (liter) }\end{array}$ & Sarang & $\begin{array}{l}\text { Jumlah } \\
\text { (liter) }\end{array}$ \\
\hline 1 & M. Nawir & 9 & 55,8 & 5 & 31 & 4 & 24,8 \\
\hline 2 & Ismail & 8 & 49,6 & 6 & 37,2 & 2 & 12,4 \\
\hline 3 & Risal & 7 & 43,4 & 6 & 37,2 & 1 & 6,2 \\
\hline 4 & Suardi & 6 & 37,2 & 5 & 31 & 1 & 6,2 \\
\hline 5 & Ramli & 7 & 43,4 & 6 & 37,2 & 1 & 6,2 \\
\hline 6 & Tamrin & 6 & 37,2 & 4 & 24,8 & 2 & 12,4 \\
\hline 7 & Umar & 6 & 37,2 & 4 & 24,8 & 2 & 12,4 \\
\hline 8 & Nursalim & 5 & 31 & 3 & 18,6 & 2 & 12,4 \\
\hline 9 & Amrullah & 7 & 43,4 & 3 & 18,6 & 4 & 24,8 \\
\hline 10 & Amir & 8 & 49,6 & 3 & 18,6 & 5 & 31 \\
\hline & Total & 69 & 427,8 & 45 & 279 & 24 & 148,8 \\
\hline
\end{tabular}

Tabel 1 menunjukkan jumlah cadangan awal madu di Taman Nasional Bantimurung Bulusaraung, jumlah sarang yang pada tahun 2017 sebanyak 69 dan nilai ini di dapatkan dari masing-masing responden yang aktif dalam melakukan pemanenan madu. Dalam 1 sarang warga bisa mendapatkan sebanyak 10 botol dan dalam 1 botol berisi sebanyak $620 \mathrm{ml}$ atau setara dengan 0.6 liter sehingga jumlah cadangan awal tahun 2017 sebanyak 427,8 liter.

Tabel 1 juga menunjukkan jumlah dari madu yang belum di panen yang dimana nilai tersebut termasuk dalam uraian penambahan pada tabel 2 jumlah penambahan disini sebanyak 45 koloni atau sama dengan 279 liter madu. Penambahan ini didapatkan dari jumlah madu yang belum di panen oleh warga yang disimpan untuk frekuensi panen selanjutnya biasanya, warga akan memberi tanda pada pohon yang belum di panen sehingga para pencari lebah madu yang lain tidak memanen di pohon tersebut.

Neraca fisik HHBK madu merupakan pemanfaatan hasil hutan hewani yang dilakukan oleh masyarakat desa Tompobulu pada Taman Nasional Bantimurung Bulusaraung. Adapun perhitungan neraca fisik HHBK madu dapat dilihat pada Tabel 2.

Tabel 2. Neraca fisik HHBK madu

\begin{tabular}{|c|l|c|}
\hline No & \multicolumn{1}{|c|}{ Uraian } & Neraca Fisik HHBK Madu (Liter) \\
\hline 1 & Cadangan Awal & 427,8 \\
\hline 2 & Penambahan & 279 \\
\hline 3 & Deplesi & 148,8 \\
\hline 4 & Cadangan Akhir & 558 \\
\hline
\end{tabular}

Neraca fisik HHBK madu pada Taman Nasional Bantimurung Bulusaraung oleh masyarakat desa Tompobulu di Kabupaten Pangkep Sulawesi Selatan. Dalam Tabel 6 dapat dilihat bahwa cadangan awal yang dimiliki sebanyak 427,8 liter dimana penambahan sebanyak 279 liter dan jumlah produki yang dihasilkan sebanyak 706,8 liter dalam satu tahun penelitian dan deplesi 
dengan nilai 148,8 liter yang menyisahkan cadangan 558 liter. Kondisi tersebut menunjukkan bahwa cadangan akhir madu setiap tahun akan semakin berkurang jika pengambilan madu secara terus menerus tanpa adanya upaya mengganti metode panen yang dapat memelihara keberlangsungan hidup lebah hutan agar tetap bisa berproduksi secara berkelanjutan dan lestari, maka akan terjadi kelangkaan HHBK madu. Jika hal tersebut terjadi maka akan sangat merugikan banyak pihak terkait dan lebih berdampak pada masyarakat yang menggantungkan hidupnya pada pemanfaatan HHBK tersebut.

\subsection{Neraca Moneter HHBK Madu}

Neraca moneter merupakan hasil konversi dari neraca fisik yang dimana hasil neraca moneter dapat menampilkan nilai sesungguhnya dari cadangan akhir sumberdaya. Jika terdapat perbedaan harga awal tahun dengan harga akhir tahun, sebaiknya dilakukan penyesuaian nilai yang dapat di bicarakan oleh masyarakat bersama pihak-pihak terkait. Tetapi nilai cadangan akhir tahun akan selalu sama dengan nilai cadangan awal tahun berikutnya.

Unit rent merupakan nilai yang di hitung untuk mendapatkan nilai deplesi. Pada Tabel 3 menunjukkan bahwa menghitung unit rent di butuhkan nilai pendapatan masing- masing warga yang nantinya akan di kurangi dengan biaya produksi sehingga dapat diketahui nilai unit rent dari masing-masing warga guna menghitung nilai deplesi.

Tabel 3. Perhitungan unit rent madu

\begin{tabular}{|c|c|c|c|c|c|c|}
\hline No & Nama & $\begin{array}{c}\text { Penerimaan } \\
(\mathrm{Rp})(\mathrm{A})\end{array}$ & $\begin{array}{c}\text { Biaya } \\
\text { Produksi } \\
(\mathrm{Rp})(\mathrm{B})\end{array}$ & $\begin{array}{c}\text { Laba kotor } \\
(\mathrm{Rp}) \\
(\mathrm{C}=\mathrm{A}-\mathrm{B})\end{array}$ & $\begin{array}{c}\text { Laba } \\
\text { bersih } \\
(\mathrm{Rp})(\mathrm{D})\end{array}$ & $\begin{array}{c}\text { Unit Rent } \\
(\mathrm{Rp}) \\
(\mathrm{E}=\mathrm{C}-\mathrm{D})\end{array}$ \\
\hline 1 & M.Nawir & 2.800 .000 & 2.160 .000 & 640.000 & 76.800 & 563.200 \\
\hline 2 & Ismail & 1.400 .000 & 1.080 .000 & 320.000 & 38.400 & 281.600 \\
\hline 3 & Risal & 800.000 & 540.000 & 260.000 & 31.200 & 228.800 \\
\hline 4 & Suardi & 800.000 & 540.000 & 260.000 & 31.200 & 228.800 \\
\hline 5 & Ramli & 800.000 & 540.000 & 260.000 & 31.200 & 228.800 \\
\hline 6 & Tamrin & 1.600 .000 & 1.080 .000 & 520.000 & 62.400 & 457.600 \\
\hline 7 & Umar & 1.600 .000 & 1.080 .000 & 520.000 & 62.400 & 457.600 \\
\hline 8 & Nursalim & 1.600 .000 & 1.080 .000 & 520.000 & 62.400 & 457.600 \\
\hline 9 & Amrullah & 3.200 .000 & 2.160 .000 & 1.040 .000 & 124.800 & 915.200 \\
\hline 10 & Amir & 4.000 .000 & 2.200 .000 & 1.800 .000 & 216.000 & 1.584 .000 \\
\hline & $\begin{array}{c}\text { Total } \\
\text { Keseluruhan }\end{array}$ & 18.600 .000 & 12.460 .000 & 6.140 .000 & 736.800 & 5.403 .200 \\
\hline
\end{tabular}

Tabel 3 merupakan tabel perhitungan unit rent dari HHBK madu, yang dimana nilai unit rent di jumlahkan untuk mendapatkan nilai deplesi dari neraca. Dengan total keseluruhan dari Unit rent sebesar Rp 5.403.200,- . Nilai deplesi dapat dilihat pada Tabel 4 nilai tersebut merupakan deplesi dalam satuan Rupiah. Nilai deplesi diperoleh dengan mengalikan volume pengambilan jenis sumberdaya alam dengan unit rent. Menghitung nilai ekonomi terhadap sumberdaya alam yang di ambil dari alam. Nilai inilah yang disebut sebagai nilai deplesi yang dapat dilihat pada Tabel 4. 
Tabel 4. Perhitungan nilai deplesi HHBK madu

\begin{tabular}{|r|l|c|c|c|}
\hline \multicolumn{1}{|r|}{ No } & Nama & $\begin{array}{c}\text { Jumlah SDA } \\
\text { yang di ambil } \\
\text { Qx (liter) }\end{array}$ & $\begin{array}{c}\text { Nilai unit rent } \\
\text { Ux (Rp) }\end{array}$ & $\begin{array}{c}\text { Nilai Deplesi } \\
\text { Dx (Rp) }\end{array}$ \\
\hline 1 & M. Nawir & 24,8 & 563.200 & 13.967 .360 \\
\hline 2 & Ismail & 12,4 & 281.600 & 3.491 .840 \\
\hline 3 & Risal & 6,2 & 228.800 & 1.418 .560 \\
\hline 4 & Suardi & 6,2 & 228.800 & 1.418 .560 \\
\hline 5 & Ramli & 6,2 & 228.800 & 1.418 .560 \\
\hline 6 & Tamrin & 12,4 & 457.600 & 5.674 .240 \\
\hline 7 & Umar & 12,4 & 457.600 & 5.674 .240 \\
\hline 8 & Nursalim & 12,4 & 457.600 & 5.674 .240 \\
\hline 9 & Amrullah & 24,8 & 915.200 & 22.696 .960 \\
\hline 10 & Amir & 31 & 1.584 .000 & 49.104 .000 \\
\hline & & Total & 5.403 .200 & 110.538 .560 \\
\hline
\end{tabular}

Tabel 4 merupakan nilai perhitungan dari deplesi, yang dimana deplesi di hitung untuk mengetahui seberapa besar nilai dari pengambilan madu setiap tahunnya pada satuan Rupiah Pada tahun 2017, nilai deplesi di dapatkan dari mengalikan jumlah yang di panen dengan unit rent masing-masing responden sehingga di dapatkan nilai deplesi sebesar Rp 110.538.560,-.

Neraca moneter HHBK madu merupakan pemanfaatan hasil hutan yang dilakukan oleh masyarakat desa Tompobulu di Taman Nasional Bantimurung Bulusaraung. Adapun analisis neraca moneter HHBK madu dapat dilihat pada Tabel 5.

Tabel 5. Neraca moneter HHBK madu

\begin{tabular}{|c|l|c|}
\hline No & \multicolumn{1}{|c|}{ Uraian } & Neraca Moneter HHBKMadu (Rp) \\
\hline 1 & Cadangan Awal & 53.500 .000 \\
\hline 2 & Penambahan & 34.900 .000 \\
\hline 3 & Revaluasi & 138.000 .000 \\
\hline 3 & Deplesi & 110.538 .560 \\
\hline 4 & Cadangan Akhir & 115.861 .440 \\
\hline
\end{tabular}

Pada Tabel 5 menampilkan neraca moneter yakni hasil konversi dari Tabel 3 neraca fisik ke dalam hitungan rupiah (Rp). Neraca moneter bisa menyampaikan berapa nilai sesungguhnya dari cadangan akhir sumberdaya. Sumberdaya Madu cadangan awal sebesar Rp 53.500.000,- dan di tambah dengan penambahan $\mathrm{Rp} 34.900 .000$ dengan total $\mathrm{Rp} 88.400 .000$. nilai ini kemudian di kurangkan dengan nilai deplesi sebesar Rp 110.538.560,- sehingga total cadangan akhir Rp 115.861 .440 


\subsection{Neraca Fisik HHBK Kemiri}

Neraca fisik mencakup perubahan-perubahan dalam cadangan awal, pertumbuhan, deplesi dan cadangan akhir. Sehingga volume cadangan akhir suatu tahun, akan sama jumlahnya dengan cadangan awal tahun berikutnya. Pemanfaatan HHBK merupakan perubahan dari hasil pemanfaatan manusia terhadap hutan berupa hasil hutan kayu ataupun hasil hutan bukan kayu. Kemiri dikelola secara tradisonal dan memiliki kontribusi terhadap pendapatan ekonomi setiap rumah tangga sebab buah kemiri hampir setiap hari dibutuhkan oleh masyarakat untuk bumbu masak, disamping untuk keperluan lainnya. Pengembangan tanaman kemiri di Indonesia perlu mendapat perhatian dalam meningkatkan taraf kehidupan petani dengan melihat prospek dari berbagai jenis kemiri yang di budidayakan. Di masyarakat desa Tompobulu sendiri kemiri di jual untuk memenuhi kebutuhan rumah tangga dan beberapa disimpan untuk penggunaan sendiri.

Tabel 6. Jumlah cadangan awal tahun 2017 dan jumlah kemiri yang belum di panen

\begin{tabular}{|c|c|c|c|c|}
\hline \multirow{2}{*}{ No. } & \multirow{2}{*}{ Nama } & $\begin{array}{c}\text { Jumlah cadangan } \\
\text { awal 2017 }\end{array}$ & $\begin{array}{c}\text { Jumlah kemiri } \\
\text { belum panen }\end{array}$ & $\begin{array}{c}\text { Jumlah kemiri yang } \\
\text { di panen }\end{array}$ \\
\cline { 3 - 5 } & & $\mathrm{Kg}$ & $\mathrm{Kg}$ & $\mathrm{Kg}$ \\
\hline 1 & Ilyas & 75 & 50 & 25 \\
\hline 2 & M nawir & 100 & 50 & 50 \\
\hline 3 & Suardi & 100 & 50 & 50 \\
\hline 4 & Ramli & 120 & 40 & 80 \\
\hline 5 & Tamrin & 85 & 60 & 25 \\
\hline 6 & Umar & 85 & 50 & 35 \\
\hline 7 & Nursalim & 90 & 60 & 30 \\
\hline 8 & Amborappe & 70 & 60 & 10 \\
\hline 9 & Amrullah & 160 & 60 & 100 \\
\hline 10 & Ambotang & 60 & 50 & 10 \\
\hline & Total & 945 & 530 & 415 \\
\hline
\end{tabular}

Tabel 6 menunjukkan jumlah cadangan awal pada tahun 2017 untuk HHBK kemiri sebanyak $945 \mathrm{~kg}$. Para responden juga menyimpan beberapa kg kemiri ditempat penyimpanan yang biasanya berada di bawah rumah ataupun di gudang masing-masing warga, biasanya masyarakat mengambil kemiri yang telah jatuh dan secara keseluruhan total yang belum di panen oleh masyarakat sebanyak $530 \mathrm{~kg}$ yang masuk dalam uraian penambahan pada Tabel 7.

Neraca fisik HHBK kemiri merupakan pemanfaatan hasil hutan nabati yang dilakukan oleh masyarakat desa Tompobulu di Zona Tradisional Taman Nasional Bantimurung Bulusaraung. Adapun analisis neraca fisik HHBK kemiri dapat dilihat pada Tabel 7.

Tabel 7. Neraca fisik HHBK kemiri

\begin{tabular}{|c|l|c|}
\hline No & \multicolumn{1}{|c|}{ Uraian } & Neraca Fisik HHBK Kemin $(\mathrm{Kg})$ \\
\hline 1 & Cadangan Awal & 945 \\
\hline 2 & Penambahan & 530 \\
\hline 3 & Deplesi & 415 \\
\hline 4 & Cadangan Akhir & 1.060 \\
\hline
\end{tabular}


Tabel 7 menyajikan neraca fisik kemiri pada Taman Nasional Bantimurung Bulusaraung oleh masyarakat desa Tompobulu di Kabupaten Pangkep Sulawesi Selatan. Tabel 7 menunjukkan cadangan awal yang dimiliki sebanyak $945 \mathrm{~kg}$ dengan penambahan sebanyak $530 \mathrm{~kg}$ dengan total hasil produksi $1.475 \mathrm{~kg}$ dan deplesi sebesar $415 \mathrm{~kg}$ sehingga hasil cadangan akhir $1.060 \mathrm{~kg}$. Deplesi adalah pengurangan nilai sumber daya alam sehingga cadangan akan terus menerus turun dan nilai jual akan terus berkurang. Sumberdaya alam HHBK kemiri tidak dapat digantikan dengan alat sehingga sedikit demi sedikit kemiri di desa Tompobulu akan habis, dan pengembangan tanaman kemiri di desa Tompobulu perlu mendapat perhatian yang lebih, dikarenakan nilai neraca secara fisik sudah berkurang, apalagi pengembangan ini dalam upaya untuk meningkatkan taraf kehidupan petani.

\subsection{Neraca Moneter HHBK Kemiri}

Kemiri merupakan komoditi yang mempunyai prospek pasar yang cukup luas, baik di dalam maupun di luar negeri. Kemiri mempunyai nilai ekonomi tinggi sebagai bahan produk mulai dari penyedap makanan sampai bahan baku industri dan perabot rumah tangga. Produk kemiri dapat dimanfaatkan sebagai bumbu masak, obat-obatan, minyak kemiri untuk perawatan rambut dan kecantikan, bahan baku industri sabun dan cat, kayu bakar, korek api, perabot rumah tangga, papan pengepak, pulp, dan vinir kayu lapis.

Neraca moneter merupakan hasil konversi dari neraca fisik yang dimana hasil neraca moneter dapat menampilkan nilai sesungguhnya dari cadangan akhir sumberdaya. Jika terdapat perbedaan harga awal tahun dengan harga akhir tahun, sebaiknya dilakukan penyesuaian nilai yang dapat di bicarakan oleh masyarakat bersama pihak-pihak terkait. Tetapi nilai cadangan akhir tahun akan selalu sama dengan nilai cadangan awal tahun berikutnya.

Unit rent merupakan nilai yang di hitung untuk mendapatkan nilai deplesi. Pada Tabel 8 menunjukkan bahwa menghitung unit rent di butuhkan nilai penerimaan kotor masing- masing warga yang nantinya akan di kurangkan dengan biaya produksi sehingga dapat diketahui nilai unit rent dari masing-masing warga guna menghitung nilai deplesi.

Tabel 8. Perhitungan unit rent HHBK kemiri

\begin{tabular}{|c|c|c|c|c|c|c|}
\hline \multirow[t]{2}{*}{ No } & \multirow[t]{2}{*}{ Nama } & \multirow{2}{*}{$\begin{array}{c}\text { Penerimaan } \\
\text { (A) (Rp) }\end{array}$} & \multirow{2}{*}{$\begin{array}{c}\text { Biaya } \\
\text { Produksi } \\
\text { (B) (Rp) }\end{array}$} & $\begin{array}{c}\text { Laba Kotor } \\
\text { (Rp) }\end{array}$ & \multirow{2}{*}{$\begin{array}{l}\text { Laba bersih } \\
\text { (Rp) (D) }\end{array}$} & \multirow{2}{*}{$\begin{array}{c}\text { Unit Rent } \\
(\mathrm{Rp}) \\
(\mathrm{E}=\mathrm{C}-\mathrm{D})\end{array}$} \\
\hline & & & & $(C=A-B)$ & & \\
\hline 1 & Ilyas & 500.000 & 300.000 & 200.000 & 24.000 & 176.000 \\
\hline 2 & M nawir & 950.000 & 550.000 & 400.000 & 48.000 & 352.000 \\
\hline 3 & Suardi & 950.000 & 550.000 & 400.000 & 48.000 & 352.000 \\
\hline 4 & Ramli & 1.600 .000 & 1.100 .000 & 500.000 & 60.000 & 440.000 \\
\hline 5 & Tamrin & 475.000 & 300.000 & 175.000 & 21.000 & 154.000 \\
\hline 6 & Umar & 700.000 & 550.000 & 150.000 & 18.000 & 132.000 \\
\hline 7 & Nursalim & 570.000 & 300.000 & 270.000 & 32.400 & 237.600 \\
\hline 8 & Amborappe & 200.000 & 100.000 & 100.000 & 12.000 & 88.000 \\
\hline 9 & Amrullah & 1.900 .000 & 1.650 .000 & 250.000 & 30.000 & 220.000 \\
\hline \multirow[t]{2}{*}{10} & Ambotang & 200.000 & 100.000 & 100.000 & 12.000 & 88.000 \\
\hline & Total & 8.045 .000 & 5.500 .000 & 2.545 .000 & 305.400 & 2.239 .600 \\
\hline
\end{tabular}


Tabel 8 menunjukkan perhitungan unit rent dari HHBK kemiri yang dimana nilai dari unit rent $(U x)$ oleh setiap masyarakat kemudian di kalikan dengan volume sumberdaya yang di ambil (Qx) untuk mendapatkan nilai deplesi pada Tabel 9.

\begin{tabular}{|r|r|r|r|c|}
\hline \multicolumn{1}{|r|}{ No } & \multicolumn{1}{|c|}{ Nama } & $\begin{array}{c}\text { Jumlah SDA yang di } \\
\text { ambil Qx (liter) }\end{array}$ & $\begin{array}{c}\text { Nilai unit rent } \\
\text { Ux (Rp) }\end{array}$ & $\begin{array}{c}\text { Nilai Deplesi } \\
\text { Dx (Rp) }\end{array}$ \\
\hline 1 & Ilyas & 25 & 176.000 & 4.400 .000 \\
\hline 2 & M nawir & 50 & 352.000 & 17.600 .000 \\
\hline 3 & Suardi & 50 & 352.000 & 17.600 .000 \\
\hline 4 & Ramli & 80 & 440.000 & 35.200 .000 \\
\hline 5 & Tammin & 25 & 154.000 & 3.850 .000 \\
\hline 6 & Umar & 35 & 132.000 & 4.620 .000 \\
\hline 7 & Nursalim & 30 & 237.600 & 7.128 .000 \\
\hline 8 & Amborappe & 10 & 88.000 & 880.000 \\
\hline 9 & Amrullah & 100 & 220.000 & 22.000 .000 \\
\hline 10 & Ambotang & 10 & 88.000 & 880.000 \\
\hline & Total & 415 & 2.239 .600 & 114.158 .000 \\
\hline
\end{tabular}

Tabel 9. Perhitungan nilai deplesi HHBK kemiri

Neraca moneter HHBK kemiri merupakan pemanfaatan hasil hutan yang dilakukan oleh masyarakat desa di Zona Tradisional Taman Nasional Bantimurung Bulusaraung dalam hitungan satuan Rupiah (Rp). Adapun analisis neraca moneter HHBK kemiri dapat dilihat pada Tabel 10.

Tabel 10. Neraca Moneter HHBK Kemiri

\begin{tabular}{|c|l|c|}
\hline No & \multicolumn{1}{|c|}{ Uraian } & Neraca Moneter HHBK Kemiri (Rp) \\
\hline 1 & Cadangan Awal & 18.365 .000 \\
\hline 2 & Penambahan & 10.320 .000 \\
\hline 3 & Revaluasi & 45.360 .000 \\
\hline 4 & Deplesi & 114.158 .000 \\
\hline 5 & Cadangan Akhir & -40.113 .000 \\
\hline
\end{tabular}

Pada Tabel 10 menampilkan neraca moneter yakni hasil konversi dari Tabel 8 neraca fisik ke dalam hitungan rupiah (Rp). Neraca moneter bisa menyampaikan berapa nilai sesungguhnya dari cadangan akhir sumberdaya. berdasarkan Tabel 10 sumberdaya kemiri cadangan awal hanya sebesar Rp 18.365.000,- dan di kurangi dengan nilai deplesi Rp 114.158.000,- sehingga hasil cadangan akhir (- Rp 40.113.000,-).

Menurut hasil penelitian Suprayitno (2011) Partisipasi petani dalam pengelolaan hutan kemiri memberikan kontribusi yang relatif kecil terhadap keberlanjutan manfaat hutan kemiri, yaitu hanya sekitar 10\%, karena partisipasi petani sekitar hutan kemiri tidak ideal. Petani yang dimana sebagai pihak yang langsung merasakan manfaat hutan, akhirnya menilai bahwa manfaat hutan kemiri yang mereka rasakan sangat rendah, karena produktivitasnya sudah sangat rendah sebagai akibat komposisi tegakan kemiri yang didominasi oleh tegakan berusia tua dan kurang terlatihnya petani dalam mencari metode panen yang dapat memelihara dan memproduksi kemiri secara berkelanjutan dan lestari. 


\section{KESIMPULAN DAN SARAN}

\subsection{Kesimpulan}

Pada pemanfaatan HHBK madu dan kemiri terjadi penyusutan (deplesi) yang akan terus berkurang setiap tahunnya. Tanpa adanya pengelolaan sumberdaya yang lestari maka deplesi akan terus meningkat setiap tahunnya dan akan merugikan tahun-tahun berikutnya.

\subsection{Saran}

Masyarakat dapat bekerja sama dengan pengelola Taman Nasional untuk merumuskan kebijakan pengelolaan dan mulai memperhitungkan berapa banyak yang dapat di panen setiap tahunnya dengan demikian, sumberdaya hasil hutan bukan kayu tidak terjadi kelangkaan di tahuntahun berikutnya dan juga agar instansi lain dapat bekerja sama dalam memberikan pelatihan atau pembelajaran pada masyarakat yang menggantungkan hidupnya dari mengambil sumberdaya di dalam hutan secara lestari.

\section{DAFTAR PUSTAKA}

Dewi, I., dkk. 2010. Implementasi peraturan tentang pengelolaan hutan lindung: studi kasus di kabupaten pangkep dan kabupaten maros,sulawesi selatan. Jurnal analisis kebijakan kehutanan. Vol 7 (3):195-209

Justianto, A. 2006. Dampak kebijakan pembangunan kehutanan terhadap pendapatan masyarakat miskin di Kalimantan Timur : suatu pendekatan model system neraca social ekonomi. Jurnal manajemen agribisnis. Vol 3 (1) : 37-44

Kadir, A., dkk. 2012. Analisis kondisi sosial ekonomi masyarakat sekitar taman nasional bantimurung bulusaraung, provinsi Sulawesi Selatan. Jurnal manusia dan lingkungan. Vol $19(1): 1-11$

Prihartini, i., Tedjo. 2004. Pemanfaatan ekstraktor dlam upaya peningkatan produksi dan kualitas pangan madu di kelompok peternak madu KPH Tumpang. Jurnal edikasi. Vol 1 (2):49-57

Purbaya, J.R. 2007. Mengenal dan Memanfaatkan Khasiat Madu Alami. Bandung: Penerbit Pinonir Jaya

Suhesti, E., Hadinoto.2015. Hasil hutan bukan kayu madu sialang di Kabupaten Kampar (studi kasus: kecamatan Kampar kiri tengah). Jurnal wahana foresta. Vol 10 (2) : 16-26

Suprayitno, A., dkk. 2011. Model peningkatan partisipasi petani sekitar hutan dalam pengelolaan hutan kemiri rakyat: kasus pengelolaan hutan kemiri kawasan pegunungn bulusaraung kabupaten maros provinsi Sulawesi Selatan. Jurnal sosial ekonomi kehutanan. Vol 8 (3):176-195

Yusran. 2005. Analisis performasi dan pengembangan hutan kemiri rakyat di kawasan pegunungan Bulusaraung Sulawesi Selatan. Thesis. Bogor. 